\title{
Kawasaki disease, autoimmune disorders, and cancer: a register-based study
}

\author{
Troels Munck Nielsen ${ }^{1} \cdot$ Niels Holmark Andersen ${ }^{2}$ (D) $\cdot$ Christian Torp-Pedersen $^{3,4} \cdot$ Peter Søgaard $^{1}$. \\ Kristian Hay Kragholm ${ }^{3,5}$
}

Received: 15 May 2020 / Revised: 29 July 2020 / Accepted: 3 August 2020 / Published online: 9 August 2020

(C) Springer-Verlag GmbH Germany, part of Springer Nature 2020

\begin{abstract}
Kawasaki disease has well-described cardiovascular complications. However, the association to autoimmunity and cancer in the long term is not well described. We investigated theses associations using a registry-based matched cohort follow-up study of patients diagnosed with Kawasaki disease. Patients with Kawasaki disease were included and matched 1:5 to a population control group, matched by birth year, sex and incident month of the Kawasaki disease diagnosis. A total of 820 cases $<21$ years of age were identified. Median age at diagnosis was 3 years. Median follow-up time was 12 years. Patients with KD were at higher risk of being diagnosed with ischaemic heart disease at 10 years (HR 39.94 (95\% CI 5.00-319.28)) and 30 years (HR 8.33 (95\% CI 3.03-22.91)). The 10-, 20- and 30-year risks of developing autoimmune disorders were HR 4.23 (95\% CI 3.01-5.94), HR 3.23 (95\% CI 2.44-4.29) and 2.83 (95\% CI, 2.17-3.68), all $p<0.001$. Cancer risk was increased after 30 years (HR 2.42 (95\% CI, 1.09-5.34)). All-cause mortality after 35 years was also significantly increased (HR 3.14 (95\% CI, 1.03-9.60)). Children with $\mathrm{KD}$ have increased long-term risks of ischaemic heart disease also of autoimmune disease and cancer, as well as an increased allcause mortality. The surprisingly increased risk of autoimmunity must be investigated further.
\end{abstract}

\section{What is known:}

- Kawasaki disease is characterized by acute vasculitis and inflammation that can affect the coronary arteries.

- Anti-inflammatory medicine is effective in the acute stages of the disease.

What is new:

- Children with Kawasaki disease have an increased risk of developing autoimmune disease in the long term.

- Kawasaki disease is associated with a slightly increased mortality rate driven by non-cardiovascular causes.

Keywords Cardiology $\cdot$ Vasculitis $\cdot$ Immunology $\cdot$ Paediatrics $\cdot$ Coronary arteries

Communicated by Peter de Winter

Niels Holmark Andersen

dr.holmark@gmail.com

Troels Munck Nielsen

troels.n@rn.dk

Christian Torp-Pedersen

ctp@heart.dk

Peter Søgaard

p.soegaard@rn.dk

Kristian Hay Kragholm

kdks@rn.dk
1 Department of Cardiology, Aalborg University Hospital, 9000 Aalborg, Denmark

2 Department of Cardiology, Odense University Hospital, J. B. Winsløws Vej 4, 5000 Odense, Denmark

3 Unit of Clinical Biostatistics and Epidemiology, Aalborg University Hospital, 9000 Aalborg, Denmark

4 Department of Health Science and Technology, Aalborg University, 9000 Aalborg, Denmark

5 Department of Cardiology, North Denmark Regional Hospital, 9800 Hjørring, Denmark 


\section{List of abbreviations \\ ASA Acetylsalicylic acid \\ CAA Coronary artery aneurisms \\ CABG Coronary artery bypass grafting \\ HR Hazard ratio \\ ICD International Classification of Disease \\ IVIG Intravenous immunoglobulin \\ IHD Ischaemic heart disease \\ KD Kawasaki disease \\ NPR National Patient Registry \\ PCI Percutaneous coronary procedures}

\section{Introduction}

Kawasaki disease (KD) is a self-limiting, acute febrile disease affecting children of all ages, although mainly before the fifth year. Kawasaki disease is characterized by acute vasculitis and inflammation, predominantly affecting medium sized arteries including the coronary arteries where inflammation can lead to coronary artery aneurisms (CAA) [1] and at a later stage cause coronary thrombosis [2]. Due to the cardiac involvement, KD is the leading cause of acquired heart disease in children in the western world $[3,4]$.

The diagnosis is based on clinical criteria with fever of $>$ 5 days and the presence of $\geq 4$ out of 5 clinical features (erythema of the extremities, erythematous rash, conjunctivitis, oral changes and cervical lymphadenopathy) $[1,5]$; however, no specific test or aetiology has been established. Standard treatment is intravenous immunoglobulin (IVIG) and lowdose acetylsalicylic acid (ASA) [3, 6]. Studies indicate that $\mathrm{KD}$ is triggered by an abnormal autoimmune response caused by an infection [7-9], but no definitive agent has been found. The potent anti-inflammatory effect of immunoglobulin treatment in the early stages of the disease indicates that autoimmunity or auto-inflammation could be essential in $\mathrm{KD}[10$, 11], which one of these factors that are the most important has not been clarified [10]. However, this observation could suggest that KD might be a severe autoimmune manifestation in a child predisposed to other autoimmune diseases later in life. Yet, no long-term follow-up studies have yet investigated this theory.

The objective of the present study was to investigate both long-term outcomes including all-cause mortality, ischemic heart disease, but also with a special focus on the development of autoimmune disease and cancer in patients diagnosed with KD in Denmark.

\section{Methods}

\section{Study design and patients}

This is a nationwide, registry-based matched cohort follow-up study of incident KD during 1981-2015 in Denmark. Any hospitalization and diagnoses (primary and secondary) since 1977 are recorded upon discharge in the Danish National Patient Registry (NPR). We identified all patients with a registered diagnosis of KD since 1981, when the diagnosis code was made available. These data include outpatients and data from hospital admissions. General practitioners do not register diagnoses in the national registers. Before 1994, we used the International Classification of Disease version 8 (ICD-8) 446.1 and from 1994 onwards; we used the ICD-10 code M30.3 to identify patients with KD. We only included KD patients below 21 years of age and matched KD patients 1:5 to population controls using birth year, gender and incident month of the KD diagnosis as matching criteria. Twenty KD patients were not successfully matched to cohort controls. These patients all had KD diagnosed in the last month (December 2015) of the observation period, leaving $820 \mathrm{KD}$ patients and 4080 cohort controls.

\section{Data sources}

All Danish residents are given a unique personal social security number, either upon birth or upon immigration, which allows exact linkage between nationwide registries. The Civil Registration System (CRS), under which this unique identifier is stored, also keeps information regarding gender, birth date and death including date of death. The Danish Cause of Death Register contains information on the presumed cause of death. If an autopsy was performed the cause of death is based on those findings. In addition to be the primary source of identification of KD patients, we also used the NPR to assess outcomes of stroke, heart failure, mitral valve regurgitation, autoimmune diseases, cancer, ischaemic heart disease (IHD) and acute myocardial infarction. Similarly, the register was used to identify percutaneous coronary interventions $(\mathrm{PCI})$ and coronary artery bypass grafting (CABG), although no patients had such procedures performed. The Danish National Prescription Registry, which holds information on all redeemed prescription medications since 1995, enabled us to assess whether patients were prescribed and redeemed any ASA and/or anticoagulants in the course after KD.

\section{Outcomes}

From the initial KD diagnosis, with mortality as competing risk we studied mortality and the time to event of the following outcomes: ischemic heart disease, stroke, heart failure, 
mitral valve regurgitation, $\mathrm{PCI}$ or $\mathrm{CABG}$, cancer and all-cause mortality. According to the study by Eaton et al. [12] we analysed multiple autoimmune diseases (thyrotoxicosis, autoimmune thyroiditis, type 1 diabetes, primary adrenocortical insufficiency, celiac disease, pernicious anaemia, autoimmune haemolytic anaemia, idiopathic thrombocytopenic purpura, Henoch-Schönlein purpura, multiple sclerosis, Guillain Barre syndrome, iridocyclitis, Wegener's granulomatosis, Crohn's disease, ulcerative colitis, primary biliary cirrhosis, chronic hepatitis, interstitial cystitis, endometriosis, pemphigoid, pemphigus, psoriasis vulgaris, psoriasis arthritis, alopecia areata, vitiligo, rheumatoid arthritis, dermatopolymyositis, myositis, polymyalgia rheumatic, myasthenia gravis, systemic sclerosis, systemic lupus erythematosus and Sjögren's syndrome). All outcomes were analysed and compared with an age- and sex-matched control group. All patients were followed until death, any non-fatal event or until 31 December 2015, whichever came first.

\section{Statistical analysis}

Clinical characteristics were described as follows: Categorical variables were presented as counts and percentages and were analysed with the $\chi^{2}$ test; and continuous variables were presented as median and 25-75\% percentiles and analysed using the Wilcoxon-Mann-Whitney test. Outcome rates were compared between the two groups by using Cox proportional hazards analysis. A two-sided $p$ value of less than 0.05 was considered statistically significant. Data management and statistical analyses were performed using SAS version 9.4 and R, version 3.5.0.

\section{Ethics}

This study was approved by the Danish Data Protection Agency (Ref. number 2007-58-0015, local number GEH-2014-018, Isuite number 02736). Ethical approval is not required for register-based studies in Denmark. All analyses were performed on secure servers placed at Statistics Denmark.

\section{Results}

During 1981-2015, 820 patients were registered in the Danish National patient Registry with a KD hospitalization in Denmark. This population was compared with 4080 ageand sex-matched controls.

The median age at KD diagnosis was 3 years (Q1-Q3; $2-$ 6); 359 children ( $44 \%$ ) were $<5$ years. The median follow-up period was 12 years (Q1-Q3; 5-20); and 61.3\% were males.

Data on low dose ASA (75 mg) was available from year 1995 and onwards. During 1995-2015, 640 cases with KD were identified and 246 patients $(38.44 \%)$ redeemed a prescription for ASA within the first 90 days after KD (Table 1).

\section{All-cause mortality}

During the study period, five $(0.6 \%)$ patients died in the $\mathrm{KD}$ group, none of a presumed cardiovascular cause. The median time to death for the 5 patients in the KD group was 20 years compared with 14.5 years for the eight patients in the control group. The deaths consisted of intoxications and accidents, although one case was a sudden unexpected death in infancy, and one died due to complications to juvenile rheumatoid arthritis. In comparison, $8(0.2 \%)$ individuals in the control group died, where one died from a presumed cardiovascular cause.

All-cause mortality was significantly higher in the $\mathrm{KD}$ group at 35 years of follow-up, HR 3.14 (95\% CI 1.03-9.60, $P=0.045)$ but not at 10-, 20- or 30-year follow-up. The median time to death was 20 years (Q1-Q3, [2-30]) in the KD group and 14.5 years (Q1- Q3, [3-17.5]) in the control group. The median follow-up time at risk was 12 years in both groups.

\section{Cardiovascular outcomes}

KD patients were more likely to be diagnosed with ischemic heart disease compared with the control group (10 (1.2\%) vs. $6(0.1 \%))$. The risk was highest after 10 years of follow-up (HR 39.94(95\% CI 5.00-319.28, $P<0.001$ ) and 20 years of follow-up (HR 44.96 (95\% CI 5.70-354.85, $P<0.001$ ) but still significantly increased after 30 and 35 years of follow-up, HR 8.33 (95\% CI 3.03-22.91, $P<0.001)$ and HR 8.33 (95\% CI 3.03-22.91, $P<0.001)$, respectively. The median time to IHD was 0 years $(\mathrm{Q} 1-\mathrm{Q} 3[0-10])$ in the KD group and 22 years $(\mathrm{Q} 1-\mathrm{Q} 3$ [22-27]) in the control group. The median follow-up time for the risk assessment was 12 years in both groups (Table 2).

Neither patients in the KD nor control group had any revascularization done during follow-up.

The risk of stroke was not significantly higher in the $\mathrm{KD}$ group after 10 years (HR 4.99 (95\% CI $0.31-79.74, P=0.26$ ) 20 years (HR 1.43 (95\% CI 0.30-6.87), $P=0.66$ ), 30-year risk (HR 1.25 (95\% CI 0.27-5.89), $P=0.78$ ) or 35 years (HR 1.25 (95\% CI 0.27-5.90)), $\mathrm{P}=0.78$ ), and the total event rate was below 3 patients in the $\mathrm{KD}$ group versus 8 in the control group).

Three patients in the KD group were diagnosed with mitral regurgitation compared with none in the control group. None were diagnosed with heart failure during follow-up.

\section{Autoimmune disease and cancer}

Patients with KD had a higher occurrence of autoimmune disease during follow-up, with 84 patients in the $\mathrm{KD}$ group (10.5\% among 799 without prior autoimmune disease) and 162 (4.0\% among 4050 without prior autoimmune disease) in the control group. The 10-, 20-, 30- and 35-year risks of being diagnosed with autoimmune diseases after the primary KD diagnosis were all significantly increased (Table 3 ). The 
Table 1 Clinical characteristics of the study population

\begin{tabular}{|c|c|c|}
\hline Clinical characteristics & $\begin{array}{l}\text { Kawasaki disease } \\
(n=820)\end{array}$ & $\begin{array}{l}\text { Matched controls } \\
(n=4080)\end{array}$ \\
\hline Age, median $\{\mathrm{Q} 1-\mathrm{Q} 3\} ;$ (Range: $\min -\max )$ & $\begin{array}{l}3.0\{2.0-6.0\} \\
\quad(0.0-20.0)\end{array}$ & $\begin{array}{l}3.0\{2.0-6.0\} \\
\quad(0.0-20.0)\end{array}$ \\
\hline Follow-up time years, median $\{\mathrm{Q} 1-\mathrm{Q} 3\} ;$ (Range: min-max) & $\begin{array}{l}12.0\{5.0-20.0\} \\
\quad(0.0-35.0)\end{array}$ & $\begin{array}{l}12.0\{5.0-20.0\} \\
\quad(0.0-35.0)\end{array}$ \\
\hline Male, $n(\%)$ & $503(61.3)$ & $2495(61.2)$ \\
\hline Age $<5$ years, $n(\%)$ & $359(43.8)$ & $1787(43.8)$ \\
\hline $\begin{array}{l}\text { Redemption of prescription for acetylsalicylic acid within } \\
90 \text { days after inclusion }\end{array}$ & $246(38.44) *$ & 0 \\
\hline $\begin{array}{l}\text { Redemption of prescription for acetylsalicylic acid } 90 \text { days } \\
\text { after inclusion }\end{array}$ & $0^{*}$ & 0 \\
\hline
\end{tabular}

Abbreviations: Q1-Q3: 25-75\% percentiles

*Data are from 1995 and onwards, as the Danish National Prescription Registry began in 1995 and 246 of 640 cases from 1995 to 2015 redeemed a prescription for acetylsalicylic acid within the first 90 days after inclusion median time to autoimmune disease was 2 years $(\mathrm{Q} 1-\mathrm{Q} 3[0$ $12])$ in the $\mathrm{KD}$ group and 12 years $(\mathrm{Q} 1-\mathrm{Q} 3$ [5-19]) in the control group. The median follow-up time at risk was 11 years in the KD group and 12 years in the control group. The KD group also had a higher occurrence of autoimmune disease prior to the KD diagnosis, 21 (2.6\%) vs. $30(0.7 \%)$.

The occurrence and risk of cancer was increased in $\mathrm{KD}$ patients relative to controls, $9(1.10 \%)$ vs $20(0.49 \%)$, but the events appeared at a later stage (Table 3). The median follow-up time was 12 years for both groups. All data regarding outcomes and events are shown in Table 2.

\section{Discussion}

This registry-based, nationwide study of long-term outcomes of KD has three main findings: (1) KD patients have a higher risk of being diagnosed with IHD; however, none were revascularized; (2) the increased mortality risk among KD patients was caused by non-cardiovascular causes; and (3) KD patients had a highly significant risk of developing autoimmune diseases and cancer in the long term.

Treatment with IVIG and ASA has been standard inhospital care in Denmark for decades, and these treatments
Table 2 Ischemic heart disease and all-cause mortality

\begin{tabular}{|c|c|c|c|c|}
\hline Outcome & Statistics & $\begin{array}{l}\text { Kawasaki disease } \\
(n=820)\end{array}$ & $\begin{array}{l}\text { Matched controls } \\
(n=4080)\end{array}$ & $P$ value \\
\hline $\begin{array}{l}\text { Ischemic heart disease } \\
\text { (IHD) }\end{array}$ & $n(\%)$ & $10(1.2)$ & $6(0.1)$ & \\
\hline $\begin{array}{l}\text { Time to diagnosis of } \\
\text { IHD }\end{array}$ & $\begin{array}{l}\text { median }\{\mathrm{Q} 1-\mathrm{Q} 3\} \\
\text { Range: (min-max) }\end{array}$ & $\begin{array}{l}0.0\{0.0-10.0\} \\
(0.0-22.0)\end{array}$ & $\begin{array}{l}22.0\{21.0-27.0\} ; \\
(9.0-28.0)\end{array}$ & \\
\hline IHD 10-year risk & $\mathrm{HR}(95 \% \mathrm{CI})$ & $39.94(5.00-319.28)$ & & $<0.001$ \\
\hline IHD 20-year risk & HR $(95 \%$ CI $)$ & $44.96(5.70-354.85)$ & & $<0.001$ \\
\hline IHD 30-year risk & $\mathrm{HR}(95 \% \mathrm{CI})$ & $8.33(3.03-22.91)$ & & $<0.001$ \\
\hline IHD 35-year risk & HR (95\% CI) & $8.33(3.03-22.91)$ & & $<0.001$ \\
\hline $\begin{array}{l}\text { Follow-up time for risk } \\
\text { of IHD }\end{array}$ & $\begin{array}{l}\text { median }\{\mathrm{Q} 1-\mathrm{Q} 3\} \\
\text { Range: (min, } \max )\end{array}$ & $\begin{array}{l}12.0\{5.0-20.0\} \\
(0.0,35.0)\end{array}$ & $\begin{array}{l}12.0\{5.0-20.0\} \\
(0.0,35.0)\end{array}$ & \\
\hline All-cause mortality & $\begin{array}{l}n, \text { Kaplan-Meier esti- } \\
\text { mate }(\%)\end{array}$ & $5(0.6)$ & $8(0.2)$ & \\
\hline $\begin{array}{l}\text { Time to all-cause mor- } \\
\text { tality }\end{array}$ & $\begin{array}{l}\text { median }\{\mathrm{Q} 1-\mathrm{Q} 3\} \\
\text { Range: (min, } \max )\end{array}$ & $\begin{array}{l}20.0\{2.0-30.0\} \\
\quad(0.0-33.0)\end{array}$ & $\begin{array}{l}14.5\{3.0-17.5\} \\
(1.0-21.0)\end{array}$ & \\
\hline $\begin{array}{l}\text { All-cause mortality } \\
10 \text {-year risk }\end{array}$ & $\operatorname{HR}(95 \% \mathrm{CI})$ & $3.33(0.56-19.95)$ & & 0.19 \\
\hline $\begin{array}{l}\text { All-cause mortality } \\
20 \text {-year risk }\end{array}$ & HR $(95 \%$ CI) & $2.15(0.56-8.31)$ & & 0.27 \\
\hline $\begin{array}{l}\text { All-cause mortality } \\
30 \text {-year risk }\end{array}$ & HR $(95 \%$ CI) & $2.51(0.75-8.32)$ & & 0.13 \\
\hline $\begin{array}{l}\text { All-cause mortality } \\
\text { 35-year risk }\end{array}$ & HR $(95 \%$ CI $)$ & $3.14(1.03-9.60)$ & & 0.045 \\
\hline
\end{tabular}


Table 3 Autoimmune disease and cancer during follow-up

\begin{tabular}{|c|c|c|c|c|}
\hline Outcome & Statistics & $\begin{array}{l}\text { Kawasaki disease } \\
(n=820)\end{array}$ & $\begin{array}{l}\text { Matched controls } \\
(n=4080)\end{array}$ & $P$ value \\
\hline $\begin{array}{l}\text { Autoimmune disease prior to } \\
\mathrm{KD} / \text { inclusion }\end{array}$ & $n(\%)$ & $21(2.6)$ & $30(0.7)$ & \\
\hline Autoimmune disease after KD & $n(\%)$ & $84(10.5)$ & $162(4.0)$ & \\
\hline $\begin{array}{l}\text { Time to diagnosis of autoimmune } \\
\text { disease after } \mathrm{KD}\end{array}$ & $\begin{array}{l}\text { Median } \\
\{\text { Q1-Q3\} } \\
\text { Range: (min, } \\
\text { max) }\end{array}$ & $\begin{array}{l}2.0(0.0-12.0) \\
(0.0-28.0)\end{array}$ & $\begin{array}{l}12.0(5.0-19.0) \\
(0.0-35.0)\end{array}$ & $<0.001$ \\
\hline Autoimmune disease 10 -year risk & $\operatorname{HR}(95 \% \mathrm{CI})$ & $4.23(3.01-5.94)$ & & $<0.001$ \\
\hline Autoimmune disease 20 -year risk & $\mathrm{HR}(95 \% \mathrm{CI})$ & $3.23(2.44-4.29)$ & & $<0.001$ \\
\hline Autoimmune disease 30 -year risk & $\mathrm{HR}(95 \% \mathrm{CI})$ & $2.83(2.17-3.68)$ & & $<0.001$ \\
\hline Autoimmune disease 35 -year risk & $\mathrm{HR}(95 \% \mathrm{CI})$ & $2.81(2.16-3.66)$ & & $<0.001$ \\
\hline Cancer after KD & $n(\%)$ & $9(1.1)$ & $20(0.5)$ & - \\
\hline $\begin{array}{l}\text { Time to diagnosis of cancer after } \\
\text { KD }\end{array}$ & $\begin{array}{l}\text { median } \\
\{Q 1-Q 3\} \\
\text { Range: (min, } \\
\text { max) }\end{array}$ & $\begin{array}{l}10.0(4.0-21) \\
(0.0-24.0)\end{array}$ & $\begin{array}{l}13.5(6.0-23.5) \\
(1.0-32.0)\end{array}$ & - \\
\hline Cancer 10-year risk & $\mathrm{HR}(95 \% \mathrm{CI})$ & $2.80(0.94-8.34)$ & & 0.065 \\
\hline Cancer 20-year risk & $\mathrm{HR}(95 \% \mathrm{CI})$ & $2.16(0.83-5.63)$ & & 0.11 \\
\hline Cancer 30-year risk & $\mathrm{HR}(95 \% \mathrm{CI})$ & $2.42(1.09-5.34)$ & & 0.029 \\
\hline Cancer 35-year risk & $\mathrm{HR}(95 \% \mathrm{CI})$ & $2.30(1.05-5.04)$ & & 0.039 \\
\hline
\end{tabular}

represent the most important means to reduce the development of CAA and prevent cardiovascular death [3, 13]. However, we are still far from preventing coronary artery involvement in KD. A previous Danish registry study including a review of medical records for $284 \mathrm{KD}$ patients overlapping with our study period (1996-2008) showed more than one in 10 children developed CAA despite $91.5 \%$ received IVIG treatment [14]. Moreover, 19\% developed CAA and $28 \%$ a cardiac complication in the UK and Ireland study even though $94 \%$ were treated with IVIG [15]. So, a more specific immunotherapy may be warranted if the incidence of CAA in KD should be reduced [16].

However, the long-term results in the present study indicate that the cardiovascular consequences of being diagnosed with IHD as a child with KD are not so dire. Even though a significant number of children were diagnosed with ischemic heart disease, we did not find any cardiovascular deaths among the KD patients, which indicated that aspirin and timely follow-up can prevent severe cardiovascular complications including the need for revascularisation.

The significantly higher risk of developing any autoimmune diseases in this cohort seems to link KD to a broader spectrum of autoimmunity. Few studies have previously shown a higher prevalence and risk of coeliac, allergy and atopy after KD [17-19], and our data strongly support these findings. The substantially shorter median time to an autoimmune diagnosis in the KD patients and the increasing $\mathrm{HR}$ at 30 and 35 years of follow-up indicate a link between KD and autoimmune disease. Moreover, the KD group had a higher occurrence of autoimmune diseases prior to the KD diagnosis, which may indicate that Kawasaki disease may be triggered by different potent viral agents in both children prone to or already suffering from autoimmune disease. The recent observations that link SARS Covid-19 and Kawasaki disease may be the consequences of pandemic exposure of a new virus that activates the immune system in children prone to abnormal autoimmune reactions [20]. For these reasons, exact diagnosis and fast treatment of children suspected for $\mathrm{KD}$ is crucial to reduce the autoimmune response.

How autoimmunity and KD are linked is not known [10]. The lack of an identified pathogen [11], the different responses to $\mathrm{KD}$ depending on origin [3], and the complex interplay between neutrophils, CD8+ T cells, dendritic cells, and monocyte/macrophages [21] leave more questions than answers. Activation of the interleukin pathways is a part of the initial stages of the disease [21-23] in form of activated signalling pathways of the innate immune system (Interleukines-1, -6, -17A) [23]. However, increased levels of immune complexes are also well described in KD patients suggesting a circulating or tissue antigen [24, 25]. So it seems that countless conceivable pathophysiological mechanisms exist and it is interesting to investigate whether this mysterious immune activation triggers autoimmunity on the long term or whether $\mathrm{KD}$ is a demonstration of the individual patient's autoimmune abilities. Our findings may therefore serve as an additional tool in understanding the aetiology behind KD 
but also change how we construct follow-up strategies for children with $\mathrm{KD}$ and potentially reduce the burden of autoimmune disease over time.

We also found that KD patients had a slightly higher risk of developing cancer in the very long term. However, the HRs were only significant after 30 and 35 years at risk. Cancer in KD patients has been described previously in a large registry-study including $3469 \mathrm{KD}$ patients [26]. The exact link between $\mathrm{KD}$ and cancer is not known, but there is a well-described association between autoimmunity and cancer [27, 28], so larger and more detailed studies are warranted to shed light on how the triad of $\mathrm{KD}$, autoimmune disease. and cancer interacts.

\section{Limitations}

This study has several limitations. Our study is observational, meaning that the associations we found may not be causal. Due to the registry-based design, potential outcomes could have been missed and therefore documented incorrectly, which could increase the risk of underdiagnosing outcomes. Moreover, mild cases may not have been diagnosed. Information regarding redeemed medication including ASA was only available from 1995 and onwards, meaning we do not know the extent of ASA treatment before 1995 . Despite a relatively long study period, with a maximum of 35 years of follow-up time, for a select number of subjects, adverse cardiovascular events and deaths may occur after many years and our follow-up period may have been too short to fully capture all adverse events related to $\mathrm{KD}$. Thus, this study should be repeated in the future when further follow-up time becomes available.

\section{Conclusion}

Patients diagnosed with KD had significantly more cardiovascular disease; however, only a slightly increased mortality rate driven by non-cardiovascular causes. There was a noticeably increased risk of developing autoimmune disease in patients with $\mathrm{KD}$ during childhood, which indicates that $\mathrm{KD}$ is linked to autoimmunity. The risk of cancer was also slightly increased, but not until 30 years of risk time.

Authors' contributions TM Nielsen conceptualized and designed the study, designed the data collection, collected data, and carried out all analyses and calculations, drafted the initial manuscript and reviewed and revised the final manuscript.

NH Andersen conceptualized and designed the study, designed the data collection, drafted the initial manuscript, and reviewed and revised the final manuscript.

$\mathrm{KH}$ Kragholm conceptualized and designed the study, designed the data collection, collected data, and carried out all analysis and calculations, drafted the initial manuscript and reviewed and revised the final manuscript.
P Søgaard contributed to the design, supervised the data collection, contributed to the design of the study, and critically reviewed the final manuscript.

C Torp-Pedersen contributed to the design of the study, supervised the data collection, and critically reviewed all analyses and calculations as well as the final manuscript.

\section{Compliance with ethical standards}

Conflict of interest The authors declare that they have no conflict of interest.

\section{References}

1. Amano S, Hazama F, Kubagawa H, Tasaka K, Haebara H, Hamashima Y (1980) General pathology of Kawasaki disease. On the morphological alterations corresponding to the clinical manifestations. Acta Pathol Jpn 30:681-694

2. Gersony WM (2009) The adult after Kawasaki disease the risks for late coronary events. J Am Coll Cardiol 54:1921-1923. https://doi. org/10.1016/j.jacc.2009.06.057

3. Mccrindle BW, Rowley AH, Newburger JW et al (2017) Diagnosis, treatment, and long-term management of Kawasaki disease: a scientific statement for health professionals from the American Heart Association. Circulation 25(135):e927-e999. https://doi.org/10.1161/CIR.0000000000000484

4. Miura M, Kobayashi T, Kaneko T et al (2018) Association of severity of coronary artery aneurysms in patients with Kawasaki disease and risk of later coronary events. JAMA Pediatr 7(172): e180030. https://doi.org/10.1001/jamapediatrics.2018.0030

5. Kawasaki T (1976) Acute febrile mucocutaneous syndrome with lymphoid involvement with specific desquamation of the fingers and toes in children. Arerugi. 16:178-222

6. Eleftheriou D, Levin M, Shingadia D, Tulloh R, Klein NJ, Brogan PA (2014) Management of Kawasaki disease. Arch Dis Child 99: 74-83. https://doi.org/10.1136/archdischild-2012-302841

7. Hara T, Nakashima Y, Sakai Y, Nishio H, Motomura Y, Yamasaki S (2016) Kawasaki disease: a matter of innate immunity. Clin Exp Immunol 186:134-143. https://doi.org/10.1111/cei.12832

8. Kuijpers TW, Wiegman A, van Lier RA, Roos MT, Wertheim-van Dillen PM, Pinedo S, Ottenkamp J (1999) Kawasaki disease: a maturational defect in immune responsiveness. J Infect Dis 180: 1869-1877. https://doi.org/10.1086/315111

9. Matsubara T, Ichiyama T, Furukawa S (2005) Immunological profile of peripheral blood lymphocytes and monocytes/macrophages in Kawasaki disease. Clin Exp Immunol 141:381-387

10. Marrani E, Burns JC, Cimaz R (2018) How should we classify Kawasaki disease? Front Immunol 14(9):2974. https://doi.org/10. 3389/fimmu.2018.02974

11. Kainth R, Shah P (2019) Kawasaki disease: origins and evolution. Arch Dis Child 2019-317070. https://doi.org/10.1136/archdischild2019-317070

12. Eaton WW, Rose NR, Kalaydjian A, Pedersen MG, Mortensen PB (2007) Epidemiology of autoimmune diseases in Denmark. J Autoimmun 29(1):1-9. https://doi.org/10.1016/j.jaut.2007.05.002

13. Newburger JW, Takahashi M, Beiser AS et al (1991) A single intravenous infusion of gamma globulin as compared with four infusions in the treatment of acute Kawasaki syndrome. N Engl J Med 6(324):1633-1639. https://doi.org/10.1056/ NEJM199106063242305

14. Patel A, Holman RC, Callinan LS, Sreenivasan N, Schonberger LB, Fischer TK, Belay ED (2013) Evaluation of clinical characteristics of Kawasaki syndrome and risk factors for coronary artery 
abnormalities among children in Denmark. Acta Paediatr 102:385390. https://doi.org/10.1111/apa.12142

15. Tulloh RMR, Mayon-White R, Harnden A, Ramanan AV, Tizard EJ, Shingadia D, Michie CA, Lynn RM, Levin M, Franklin OD, Craggs P, Davidson S, Stirzaker R, Danson M, Brogan PA (2019) Kawasaki disease: a prospective population survey in the UK and Ireland from 2013 to 2015. Arch Dis Child 104:640-646. https:// doi.org/10.1136/archdischild-2018-315087

16. Burns JC, Franco A (2015) The immunomodulatory effects of intravenous immunoglobulin therapy in Kawasaki disease. Expert Rev Clin Immunol 11:819-825. https://doi.org/10.1586/ 1744666X.2015.1044980

17. Stagi S, Simonini G, Ricci L, de Martino M, Falcini F (2006) Coeliac disease in patients with Kawasaki disease. Is there a link? Rheumatology. Rheumatology (Oxford) 45(7):847-850. https:// doi.org/10.1093/rheumatology/kel007

18. Webster RJ, Carter KW, Warrington NM et al (2011) Hospitalisation with infection, asthma and allergy in Kawasaki disease patients and their families: genealogical analysis using linked population data. PLoS One 6:e28004. https://doi.org/10. 1371/journal.pone.0028004

19. Hwang C-Y, Hwang Y-Y, Chen Y-J, Chen CC, Lin MW, Chen TJ, Lee DD, Chang YT, Wang WJ, Liu HN (2013) Atopic diathesis in patients with Kawasaki disease. J Pediatr J Pediatr 163:811-815. https://doi.org/10.1016/j.jpeds.2013.03.068

20. Jones VG, Mills M, Suarez D et al (2020) COVID-19 and Kawasaki disease: novel virus and novel case. Hosp Pediatr 7: hpeds.2020-0123. Online ahead of print. https://doi.org/10.1542/ hpeds.2020-0123

21. Newburger JW, Takahashi M, Burns JC (2016) Kawasaki disease. J Am Coll Cardiol 12(67(14)):1738-1749. https://doi.org/10.1016/j. jacc.2015.12.073
22. Menikou S, Langford PR, Levin M (2019) Kawasaki disease: the role of immune complexes revisited. Front Immunol 12(10):1156. https://doi.org/10.3389/fimmu.2019.01156

23. Hoang LT, Shimizu C, Ling L, Naim ANM, Khor CC, Tremoulet AH, Wright V, Levin M, Hibberd ML, Burns JC (2014) Global gene expression profiling identifies new therapeutic targets in acute Kawasaki disease. Genome Med 6:541. https://doi.org/10.1186/ s13073-014-0102-6

24. Ono S, Onimaru T, Kawakami K, Hokonohara M, Miyata K (1985) Impaired granulocyte chemotaxis and increased circulating immune complexes in Kawasaki disease. J Pediatr 106:567-570. https://doi. org/10.1016/S0022-3476(85)80073-1

25. Mason WH, Jordan SC, Sakai R, Takahashi M, Bernstein B (1985) Circulating immune complexes in Kawasaki syndrome. Pediatr Infect Dis 4:48-51. https://doi.org/10.1097/00006454-19850100000012

26. Yu KH, Kuo CF, Huang LH, Huang WK, See LC (2016) Cancer risk in patients with inflammatory systemic autoimmune rheumatic diseases. A nationwide population-based dynamic cohort study in Taiwan. Medicine (Baltimore) 95:e3540. https://doi.org/10.1097/ MD.0000000000003540

27. Giat E, Ehrenfeld M, Shoenfeld Y (2017) Cancer and autoimmune diseases. Autoimmun Rev 16:1049-1057. https://doi.org/10.1016/ j.autrev.2017.07.022

28. Beyaert R, Beaugerie L, Van Assche G et al (2013) Cancer risk in immune-mediated inflammatory diseases. Mol Cancer 29(12):98. https://doi.org/10.1186/1476-4598-12-98

Publisher's note Springer Nature remains neutral with regard to jurisdictional claims in published maps and institutional affiliations. 